Check for updates

Cite this: RSC Adv., 2020, 10, 35709

\section{Non-equilibrium atmospheric pressure plasma assisted degradation of the pharmaceutical drug valsartan: influence of catalyst and degradation environment}

\author{
A. Raji, ${ }^{\text {ab }}$ K. Navaneetha Pandiyaraj, (D) *b D. Vasu, ${ }^{\text {b M. C. Ramkumar, }{ }^{c} \text { R. R. Deshmukh }}{ }^{d}$ \\ and V. Kandavelu ${ }^{a}$
}

This paper investigated the degradation of the pharmaceutical drug Valsartan (VS) using non-equilibrium atmospheric pressure plasma (NEAPP) with various operating conditions. The heterogeneous photocatalyst ZnO nanoparticles (NP's) were synthesized using a hydrothermal process. The morphology, chemical composition and structure of as-synthesized ZnO NPs were examined by Field Emission Scanning Electron Microscopy (FE-SEM), Fourier Transform Infrared Spectroscopy (FTIR) and Xray diffraction (XRD) analysis. Then, VS degradation was examined in three subsequent treatment conditions including plasma treatment alone, the combination of plasma with as-prepared ZnO NPs and various environments (air, oxygen and hydrogen peroxide) at fixed plasma operating potential and treatment time. The degradation efficiency of plasma-treated VS by various conditions was observed using UV-visible spectroscopy. Optical Emission Spectrometry (OES) was used to characterize the distribution and emission intensity of various reactive species $\left(\mathrm{OH}^{\circ}, \mathrm{N}_{2}\right.$-SPS and $\left.\mathrm{O}\right)$ during the degradation processes which plays a vital role in the degradation of VS. The role of $\mathrm{OH}^{\cdot}$ and $\mathrm{H}_{2} \mathrm{O}_{2}$ during the degradation process was further examined by chemical dosimetry and spectroscopic techniques. Furthermore, $\mathrm{pH}$, conductivity and TOC of the untreated and plasma-treated VS were also investigated. The results on the degradation of VS showed that plasma treatment combined with ZnO NP's has a significant effect on degradation of molecules of VS than degradation processes carried out by other experimental conditions due to the formation of higher concentrations of various reactive oxygen and nitrogen species during the degradation processes.
Received 27th June 2020 Accepted 7th September 2020

DOI: 10.1039/d0ra05608a

rsc.li/rsc-advances diseases like heart disease, hypertension (high blood pressure), diabetes, stroke, asthma and cancer respectively. Valsartan (VS) (3-methyl-2-[pentanoyl-[[4-[2-(2H-tetrazol-5-yl)phenyl]phenyl] methyl]amino]-butanoic acid) is an Angiotensin II receptor blockers (ARBs), ${ }^{2}$ used to treat hypertension, cardiovascular diseases and diabetic kidney diseases. ${ }^{3}$ According to WHO report (2013), more than 1.5 billion people suffer from cardiovascular diseases ${ }^{4}$ and hence worldwide consumption of valsartan is significantly increased. Prolonged consumption of this drug is reported to produce a severe allergic reaction, difficulty in breathing, depression and vision problems. On the other hand, valsartan given/prescribed for the treatment of hypertension, is not completely metabolised $(>96 \%$ excreted unchanged) $)^{5}$ and eliminated as a biologically active compound to the environment which adversely affects aquatic life. ${ }^{6}$ Recent studies about waste water (WW)/sewage treatment plant (STP) reported that, valsartan is one of the most existing contaminations compared with other commonly used drugs. ${ }^{7}$ For instance, around $6.0 \mu \mathrm{g} \mathrm{L} \mathrm{L}^{-1}$ of VS in WW/STP, ${ }^{8} 19.8 \mu \mathrm{g} \mathrm{L}{ }^{-1} \mathrm{VS}$ in hospital effluent ${ }^{7}$ and $0.09 \mathrm{ng} \mathrm{L}^{-1}$ VS in marine and estuarine 
water (San Francisco Bay, in the USA) has found. Even though, the presence of pharmaceutical compounds in very few extent in the range of nanogram level, it can produce acute and chronic effects on human health and aquatic life. ${ }^{9}$

For these reasons, various attempts have been made to remove pharmaceuticals compounds from waste water. Various conventional methods such as adsorption, coagulation and filtration has been involved to degrade the pharmaceutical compound containing waste water. However, Conventional treatment method cannot completely degrade the pharmaceutical compounds ${ }^{\mathbf{1 0 , 1 1}}$ and it generates the secondary pollutants. Advanced Oxidation Process (AOP's) is one of the very active methods to overpower the limitation of conventional treatment methods. ${ }^{12-14}$ In AOP, various reactive oxygen and nitrogen species (ROS and RNS) such as $\mathrm{OH}^{\cdot}, \mathrm{O}, \mathrm{NO}^{2-}, \mathrm{NO}^{3-}$, and $\mathrm{H}_{2} \mathrm{O}_{2}$ during the degradation process which powerfully attack the toxic organic pollutants and convert them into nontoxic substance such as $\mathrm{CO}_{2}$ and $\mathrm{H}_{2} \mathrm{O} \cdot{ }^{15,16}$ Nevertheless, in many cases, instead of complete oxidation, it produce partial oxidation products and it again generate secondary pollutants to the environment.

Recently, non-equilibrium atmospheric pressure plasma (NEAPP) have great potential of complete oxidation of pharmaceutical compounds present in waste water via the production of various primary $\left(\mathrm{Ar}^{*}, \mathrm{O}_{2}^{*}, \mathrm{e}^{*-}, \mathrm{N}_{2}^{*}\right.$ and $\left.\mathrm{H}_{2} \mathrm{O}^{*}\right)$ and secondary reactive species $\left(\mathrm{OH}^{\circ}, \mathrm{O}, \mathrm{O}_{3}\right.$ and $\left.\mathrm{H}_{2} \mathrm{O}_{2}\right)$ at gas phase and gas-water interface. These primary and secondary reactive species can efficiently degrade the organic pollutants present in the waste water. $^{\mathbf{1 7}, \mathbf{1 8}}$ Jean Marie Herrmann ${ }^{\mathbf{1 9}}$ reported that, heterogeneous photocatalyst $\left(\mathrm{TiO}_{2}\right)$, totally degrade and mineralize large variety of organic and inorganic aqueous pollutant into $\mathrm{CO}_{2}$ and harmless inorganic anions.

Hence, we attempt to degrade the VS compounds via NEAPP at various operating conditions such as Ar plasma, the combination of Ar plasma with ZnO NP's and various environments (air, oxygen and hydrogen peroxide). The choice of $\mathrm{ZnO}$ is on the basis of its cost effectiveness, thermal stability at room temperature, high electron mobility, high photochemical reactivity, stability to photo-corrosion and low toxicity than other catalyst. $^{20,21}$ Furthermore, it was synthesized by hydro-thermal method and was characterized by various techniques such as Field-Emission Scanning Electron Microscopy (FE-SEM), Fourier transform infrared spectroscopy (FTIR) and X-ray diffraction (XRD) studies. The influence of various operating conditions on degradation of VS aqueous solution was examined comprehensively. Then, vS degradation was examined in three subsequent treatment conditions including plasma treatment alone, the combination of plasma with as-prepared ZnO NP's and various environments (air, oxygen and hydrogen peroxide) at fixed plasma operating potential and treatment time.

\section{Experimental procedure}

\subsection{Materials and methods}

Zinc acetate dihydrate $\left(\mathrm{Zn}\left(\mathrm{CH}_{3} \mathrm{COO}\right)_{2} \cdot 2 \mathrm{H}_{2} \mathrm{O}\right)$ was procured from Sigma-Aldrich, India. The commercially available Valsartan (VS) compound obtained from Dr Reddy's lab. Analytical reagent grade methanol $\left(\mathrm{CH}_{3} \mathrm{OH}\right)$, hydrochloric acids $(\mathrm{HCl})$ and sodium hydroxide $(\mathrm{NaOH})$ were purchased from Merk, India.

\subsection{Synthesis and characterization of $\mathrm{ZnO}$ nanoparticles}

For the synthesis of ZnO NP's, 0.1 M of zinc acetate solution was prepared by adding $1.1 \mathrm{~g}$ of zinc acetate in $50 \mathrm{ml}$ of methanol under continuous stirring. Subsequently, $0.2 \mathrm{~g}$ of $\mathrm{NaOH}$ was dissolved in $25 \mathrm{ml}$ of methanol, the mixed solution was added drop wise into the precursor solution to maintain the $\mathrm{pH}$ between 8 to 11. The obtained solution was further transferred into teflon-lined sealed autoclave and heated at $120{ }^{\circ} \mathrm{C}$ for 24 hours under autogenous pressure. It was then allowed to cool naturally to room temperature. After the reaction was complete, the resulting white solid product was washed with methanol at several times, filtered and then dried in a hot air oven at $60{ }^{\circ} \mathrm{C}$. Furthermore, the dried white precipitate was calcinated at $600{ }^{\circ} \mathrm{C}$ for 3 hours. ${ }^{22}$

The morphology of synthesized ZnO NP's were examined by FE-SEM (ZEISS SIGMA FESEM, Germany). The chemical composition of the ZnO NP's was analysed by FT-IR (FT/IR-4700 typeA). After the degradation process the ZnO NP's was further filtered by Whatman-40 filter paper and washed several times with DI water followed by ethanol. The obtained ZnO NP's was preheated at $60{ }^{\circ} \mathrm{C}$ and calcined at $600{ }^{\circ} \mathrm{C}$ for $3 \mathrm{~h}$. Thereafter, the chemical compositions of the recycled ZnO NP's were further confirmed by FTIR. The phase and crystallinity was observed by X-ray Diffraction (XRD) (X'pert PRO X-ray Diffractometer, PANalytical, Netherland) with $\mathrm{Cu}-\mathrm{K} \alpha(\lambda=1.5406 \AA$ and $2 \theta$ range from $\left(10-90^{\circ}\right)$ radiation.

\subsection{NEAPP reactor}

The NEAPP effluent treatment reactor was used for this treatment is shown in Fig. 1. The details of the plasma reactor are

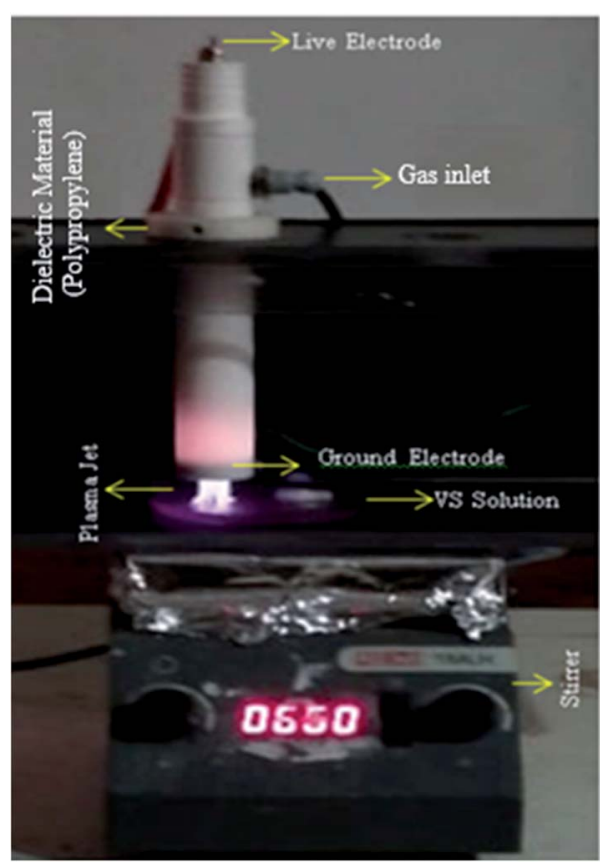

Fig. 1 NEAPP system for VS treatment. 
explained elsewhere. ${ }^{23}$ The major components of the system are plasma torch and high frequency and high voltage power supply. The plasma torch consists of rod-type live and ring shape ground electrode which made of copper. The live electrode is encapsulated by quartz tube in order to avoid arcing and was connected to an AC power supply which is operated with maximum voltage and frequency of $40 \mathrm{kV}$ and $50 \mathrm{kHz}$. The ground ring electrode was situated just below the live electrode and the distance between them was $2.5 \mathrm{~cm}$. The electrode assembly was further covered by a Teflon jacket in order to prevent electric induction during the experiment (Fig. 1). The system has a separate provision for gas inlet which is controlled by mass flow controller (AALBORG GFC37).

\subsection{Preparation of Valsartan solution and degradation process}

Initially, the stock solution having $10^{-4}$ mole concentration of VS was prepared for degradation process. In the first treatment condition, VS aqueous solution was poured into reaction flask and was positioned $5 \mathrm{~mm}$ distance below the nozzle orifice. Subsequently, argon plasma forming gas was allowed between the electrodes and high voltage was applied till the homogeneous jet was expelled via nozzle exit. The plasma plume was discharged from the nozzle exit and was allowed to pass into VS aqueous solution and treatment was carried out at optimized operating potential and treatment time of $35 \mathrm{kV}$ and $10 \mathrm{~min}$. In the second treatment condition, air was allowed into the reaction flask which leads to produce air bubbles in the aqueous solution and the same was stirred continuously using magnetic stirrer. Subsequently, the air bubbles containing aqueous solution was treated by Ar plasma at the operating parameters which was optimized for plasma treatment. Similarly VS solution was treated using $\mathrm{O}_{2}$ bubbles and also by adding $\mathrm{H}_{2} \mathrm{O}_{2}$ (1.6 $\left.\times 10^{-5} \mathrm{M}\right)$. In the final condition of degradation processes, $20 \mathrm{mg}$ of ZnO NP's was dispersed into the aqueous solution containing reaction flask and consequently $\mathrm{ZnO}$ containing VS solution was further treated by Ar plasma. The typical parameters of plasma assisted VS aqueous solution treatment are given in Table 1.

\subsection{Characterization}

2.5.1 Identification of reactive species. The information of the reactive species produced in plasma jet during the degradation of VS was examined by an optical emission spectroscopy (OES) (Ocean Optics, HR 4000CG UV-NIR, $1 \mathrm{~nm}$ ). The emission

Table 1 Typical parameters of plasma assisted VS aqueous solution treatment

Applied potential

Treatment time

Distance between live and ground electrode

Distance between plasma torch and water surface

Plasma-forming gas

Ar gas flow rate spectra were recorded in the wavelength region of 200-1100 nm. An optical fiber cable (QP400-2-SRBX) was used to collect the optical signals and was connected to the collimating lens in order to confine the field of view, increase the collection efficiency and the spatial resolution of spectrometer. The optical fiber setup was placed directly near the plasma aqueous solution treatment region using glass feed through. The spectral measurement was further diagnosed by Ocean view software.

2.5.2 Detection of $\mathrm{OH}$ radicals and $\mathrm{H}_{2} \mathrm{O}_{2}$. Terephthalic dosimetry is one of the chemical methods to quantify the $\mathrm{OH}$ radicals produced during the degradation process. Terephthalic Acid (TA) is an excellent $\mathrm{OH}$ radical scavenger at the $\mathrm{pH}$ range of 10-11. TA does not react with other reactive species such as $\mathrm{H}_{2} \mathrm{O}_{2}, \mathrm{O}^{2-}$ etc. TA molecule is reacted with $\mathrm{OH}$ radical to form 2hydroxy terephthalic acid (HTA) which can be detected by fluorescent method. UV light $(\lambda=310)$ is irradiated in the aqueous solution containing TA and HTA. The HTA molecule alone emits the radiation at $\lambda=425 \mathrm{~nm}$ in UV region, whereas TA molecule does not emit. The concentration of HTA molecules are proportional to the concentration of $\mathrm{OH}$ radicals which directly related with the intensity of fluorescence emission. ${ }^{24,25}$

Potassium titanium(Iv) oxalate $\left(\mathrm{K}_{2} \mathrm{TiO}\left(\mathrm{C}_{2} \mathrm{O}_{4}\right) 2 \mathrm{H}_{2} \mathrm{O}\right)$ method is used to determine the concentration of $\mathrm{H}_{2} \mathrm{O}_{2}$ by spectrophotometric method. Initially, $3.5 \mathrm{~g}$ of $\mathrm{K}_{2} \mathrm{TiO}\left(\mathrm{C}_{2} \mathrm{O}_{4}\right) 2 \mathrm{H}_{2} \mathrm{O}$ was added to mixed solution of concentrated $\mathrm{H}_{2} \mathrm{SO}_{4}(27.2 \mathrm{ml})$ and deionised water $(30 \mathrm{ml})$. The titanium reagent solution was further made up to $100 \mathrm{ml}$ by using DI water. For analysis, $5 \mathrm{ml}$ of titanium reagent and $5 \mathrm{ml}$ of VS solution were taken into a calibrated flask and made up to $25 \mathrm{ml}$ by adding DI water. The solution was treated by above mentioned operating conditions and the production of $\mathrm{H}_{2} \mathrm{O}_{2}$ was measured using spectrophotometer at a wavelength of $420 \mathrm{~nm} .^{26,27}$

The concentration of $\mathrm{H}_{2} \mathrm{O}_{2}\left(\mathrm{~mol} \mathrm{~L}^{-1}\right)$ was calculated as follow

$$
\left[\mathrm{H}_{2} \mathrm{O}_{2}\right]=\frac{\left(A_{\mathrm{at}}-A_{\mathrm{bt}}\right)}{37.4 x l}
$$

where $A_{\mathrm{bt}}$ and $A_{\text {at }}$ are the absorbance (at $\lambda_{\max }$ ) of the untreated and plasma treated solutions respectively. $x$ and $l$ are the volume of the solution and the path length $(\mathrm{cm})$ of the spectrophotometer cuvette respectively.

2.5.3 Investigation of degradation processes. The degradation efficiency of plasma treated VS aqueous solution with different treatment condition was observed using UV-Vis spectrophotometer (OCEAN Optics HR4000) equipped with Deuterium Halogen light source. The \% of degradation of VS aqueous solution due to plasma treatment was calculated by the following formula. ${ }^{28}$

$$
\text { Degradation }(\%)=\frac{C_{0}-C_{t}}{C_{0}} \times 100
$$

where, $C_{\mathrm{o}}$ and $C_{t}$ are the initial and final (after plasma) concentration of VS solution. The conductivity and the $\mathrm{pH}$ of the degraded VS solution were measured using a digital electrical conductivity meter-611 (Elico Ltd, India) and a digital pH meter (pHep, HANNA Instruments, USA) respectively. Total organic carbon analyzer (Shimadzu TOC-LPH) was used to 
determine the percentage of removal of carbon from the degraded aqueous VS solution. The percentage of TOC removal of VS aqueous solution was calculated using the following relation. ${ }^{29,30}$

$$
\text { TOC } \operatorname{removal}(\%)=\frac{\mathrm{TOC}_{\mathrm{in}}-\mathrm{TOC}_{\mathrm{fl}}}{\mathrm{TOC}_{\mathrm{in}}} \times 100
$$

where, $\mathrm{TOC}_{\mathrm{in}}$ and $\mathrm{TOC}_{\mathrm{fl}}$ are the initial and final concentrations of TOC in VS aqueous solution respectively.

\section{Results and discussion}

\subsection{Catalysis characterization}

The morphology of synthesized ZnO NP's was observed by FESEM which exhibits that the morphology of ZnO NP's has crystalline structure comprising of aggregated spherical particles (Fig. 2a). Fig. 2b shows the XRD pattern of synthesized $\mathrm{ZnO}$ NP's, it is clear that the synthesized ZnO NP exhibit crystalline structure with sharp peaks located at $2 \theta=31.61,34.61,36.40$,
$47.52,56.67,62.73,66.49,67.80$ and 69.10 were assigned to (100), (002), (101), (102), (110), (103), (200), (112) and (201) respectively, resembles the wurtzite hexagonal phase of $\mathrm{ZnO}$. The observed powder pattern was compared with the standard JCPDS card (36-1451). The average crystallite size of the synthesized ZnO Np catalyst was $\sim 20 \mathrm{~nm}$ calculated using the Debye-Scherer's formula $D=(0.94 \lambda) /(\beta \cos \theta)$, (where $\lambda$ is the wavelength of $\mathrm{X}$-ray ( $\mathrm{Cu}-\mathrm{K} \alpha$ radiation), $\beta$ is the full width at half maximum intensity and $\theta$ is the Bragg's angle.

\subsection{FTIR result}

The chemical composition of ZnO NP's was studied by FTIR spectra as displayed in Fig. 3a. It exhibits major peaks corresponding to stretching vibration mode of $\mathrm{ZnO}$ bond around $493 \mathrm{~cm}^{-1}$. The presence of peaks at $3432.6 \mathrm{~cm}^{-1}$ and $1628.6 \mathrm{~cm}^{-1}$ attributed to $\mathrm{O}-\mathrm{H}$ stretching vibration and the adsorption of water on the particles surface. ${ }^{31,32}$ FTIR results confirm that the major dominance of functionalities in the NP's was ZnO bond. Fig. 3b, depicted the FTIR spectrum of recycled
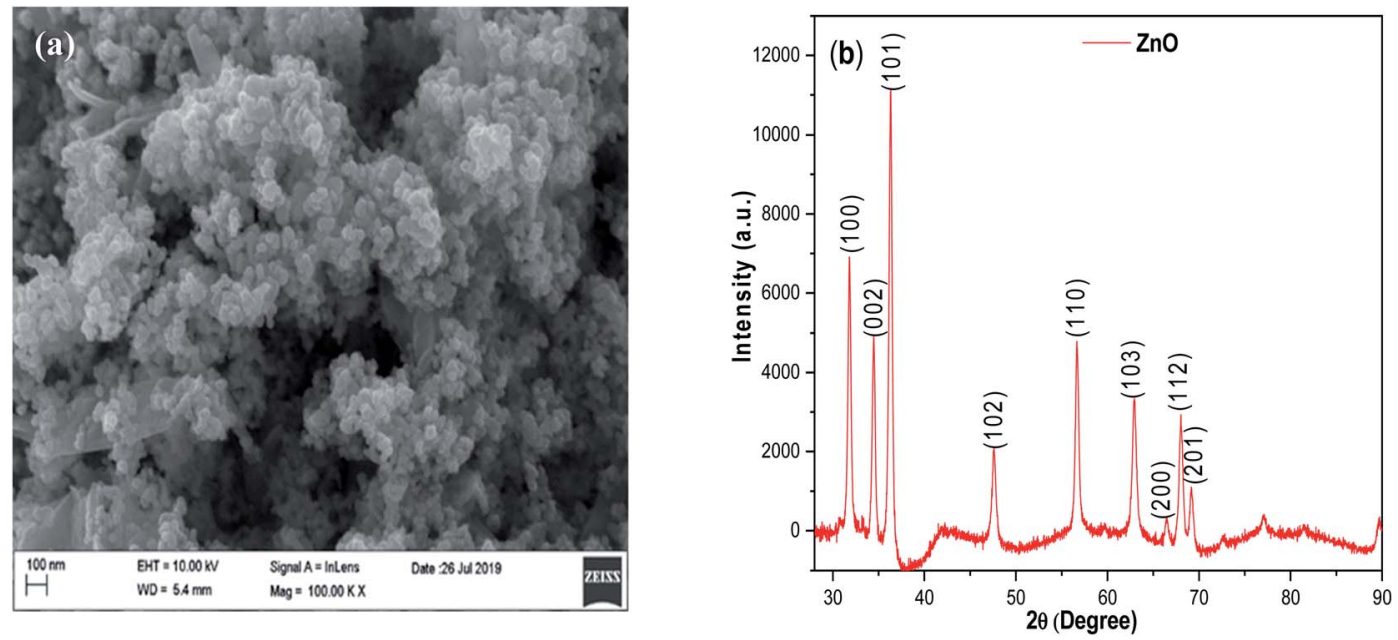

Fig. 2 (a) SEM image and (b) XRD pattern of synthesized ZnO nano particles.
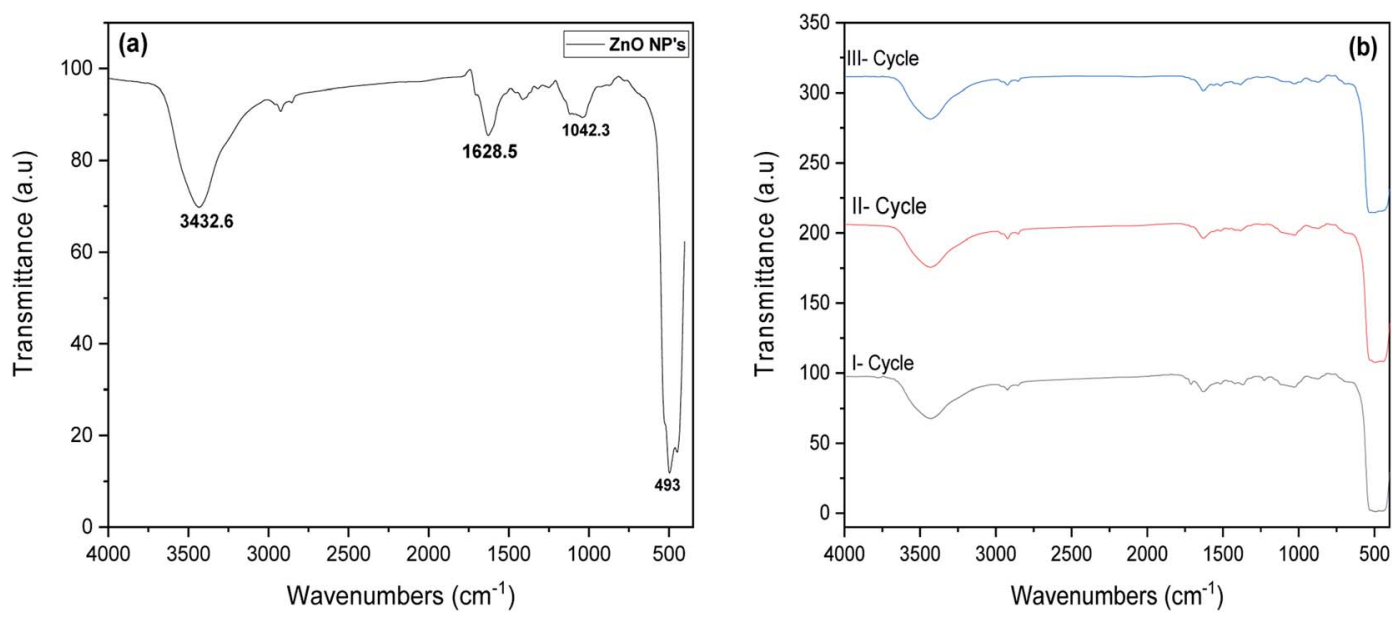

Fig. 3 FTIR spectra of (a) synthesised ZnO NP's and (b) ZnO NP's for various recycles. 


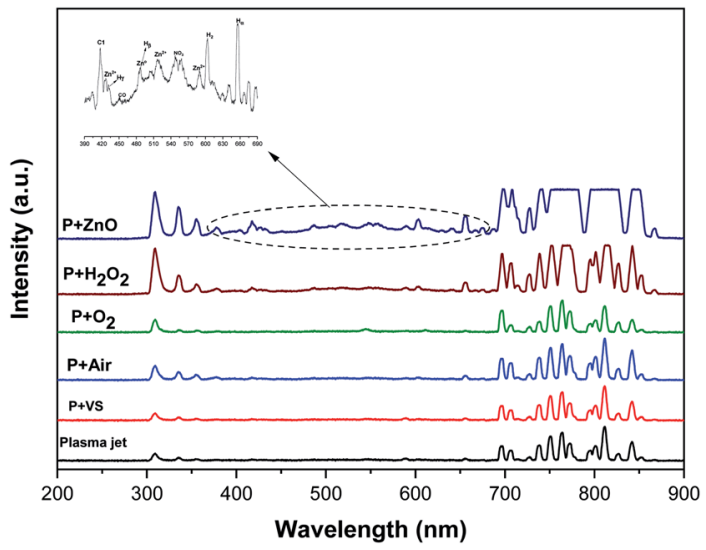

Fig. 4 Optical emission spectrum of NEAPP jet with various operating conditions.

ZnO NP's after degradation processes. It implies that after three cycles, no significant change was observed in the chemical composition of ZnO NP's which confirms the retention of functional groups before and after recycling process.

\subsection{Determination of reactive species present in various environments: OES analysis}

Fig. 4 implies the OES spectra of argon plasma jet during degradation of VS for various operating conditions. It was observed that OES spectra of Ar plasma jet (before degradation) exhibits various spectral lines due to argon excited species (Ar*) (4s $\leftarrow 4$ p lines) (690-900 $\mathrm{nm}), \mathrm{OH}$ radicals $(309 \mathrm{~nm})$, atomic oxygen $\left(3 \mathrm{~s}^{5} \mathrm{~S} \leftarrow 3 \mathrm{p}^{5} \mathrm{P}\right)(772 \text { and } 842 \mathrm{~nm})^{33,34}$ and nitrogen second positive system $\left(\mathrm{N}_{2}-\mathrm{SPS}\right)\left(\mathrm{B}^{3} \Pi_{\mathrm{g}} \leftarrow \mathrm{C}^{3} \Sigma_{\mathrm{u}}\right)(336,354$ and $380 \mathrm{~nm})$. The formation of identified reactive species such as $\mathrm{OH}^{*}, \mathrm{~N}_{2}$-SPS and $\mathrm{O}$ (reactive nitrogen species (RNS) and reactive oxygen species (ROS)) in plasma jet may be attributed to the diffusion of ambient gas molecule and moisture in the atmosphere into the plasma jet causes the formation of ROS and RNS via following reaction mechanism ${ }^{35,36}$

$$
\mathrm{Ar}^{*}+\mathrm{H}_{2} \mathrm{O} \rightarrow \mathrm{Ar}+\mathrm{OH}^{*}+\mathrm{H}
$$

$$
\begin{gathered}
\mathrm{e}^{-*}+\mathrm{O}_{2} \rightarrow 2 \mathrm{O}^{*}+\mathrm{e}^{-} \\
\mathrm{Ar}^{*}+\mathrm{N}_{2} \rightarrow \mathrm{Ar}+\mathrm{N}_{2}^{*} \\
\mathrm{~N}_{2}^{*}+\mathrm{H}_{2} \mathrm{O}_{(\text {gas })} \rightarrow \mathrm{N}_{2}+\mathrm{OH}_{(\text {gas })}+\mathrm{H}
\end{gathered}
$$

The OES spectrum of Ar plasma jet during degradation of VS aqueous solution exhibits two new peaks due to $\mathrm{H}$ line of the Balmer series such as $\mathrm{H} \alpha$ (at $655.35 \mathrm{~nm}$ ) and $\mathrm{H} \beta$ (at $588.31 \mathrm{~nm}$ ). The formation of $\mathrm{H} \alpha$ and $\mathrm{H} \beta$ may be attributed to dissociation of water molecule $\left(\mathrm{H}_{2} \mathrm{O}+\mathrm{e}^{-} \rightarrow \mathrm{OH}^{-}+\mathrm{H}^{+}+2 \mathrm{e}^{-}\right)$during the processes. However, the intensities of spectral lines due to $\mathrm{OH}^{*}$, $\mathrm{O}$ and $\mathrm{N}_{2}$-SPS were found to be increased slightly when compared with that of spectral lines observed in Ar plasma alone. A similar spectral lines was observed when degradation of VS aqueous solution carried out by the Ar plasma at various environment such as air, $\mathrm{O}_{2}$ and $\mathrm{H}_{2} \mathrm{O}_{2}$. However, the intensity of spectral lines found to be increased in the order of $\mathrm{P}+$ air $<\mathrm{P}+$ $\mathrm{O}_{2}<\mathrm{P}+\mathrm{H}_{2} \mathrm{O}_{2}$ due to the formation of higher concentration of ROS and RNS during the degradation processes with respect to the environment of degradation. When Ar plasma degradation processes combined with ZnO NP's the OES exhibits various new spectral lines at 483, 434, 517 and $590 \mathrm{~nm}$ corresponds to $\mathrm{Zn}$ and $\mathrm{Zn}^{2+}{ }^{37}$ The formation of species may be due to the interaction of plasma species with ZnO NP's cause's excitation of $\mathrm{Zn}$ during the degradation of VS which plays a significant catalytic role during degradation processes and stimulates oxidation reactions. Furthermore, the intensity of spectral line due to $\mathrm{OH}^{*}, \mathrm{O}$ and $\mathrm{N}_{2}$-SPS were increased substantially compared with the degradation processes carried out at various environment due to the formation of higher concentration of reactive species than the other treatment condition which will be discussed more detail in section 3.4.

\subsection{Investigation of plasma treated VS solution with different environment-UV analysis}

Fig. 5a, shows the UV-vis absorbance spectra of VS aqueous solution degraded as a function of various treatment conditions. The UV-vis spectrum corresponding to untreated VS
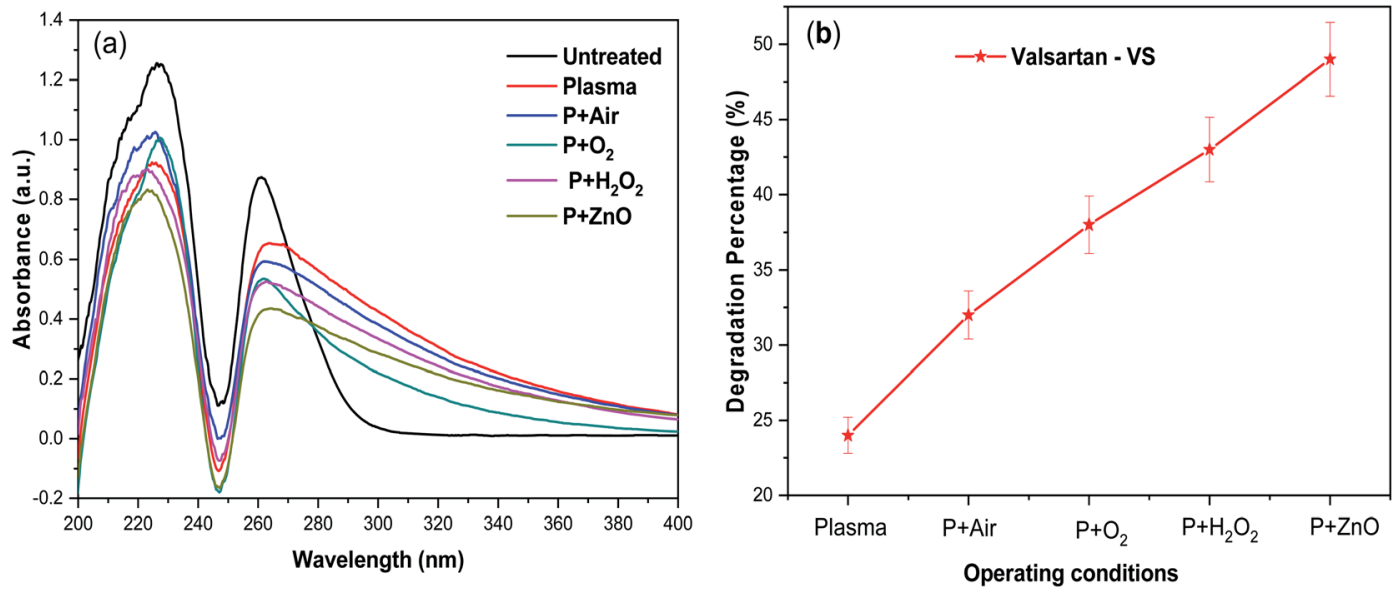

Fig. 5 (a) UV-vis spectra of the plasma-treated VS drug and (b) degradation percentage in presence of various operating conditions. 
Table 2 Comparison of degradation of VS by this technique with other treatment methods

\begin{tabular}{|c|c|c|c|c|c|}
\hline $\mathrm{Sl} / \mathrm{no}$ & $\begin{array}{l}\text { Treatment } \\
\text { method }\end{array}$ & Catalyst & $\begin{array}{l}\text { Treatment time } \\
\text { (min) }\end{array}$ & $\begin{array}{l}\% \text { of degradation } \\
\text { efficiency }\end{array}$ & Ref. \\
\hline 1 & $\mathrm{AOP}$ & Photo-Electro-Fenton & 90 & $70 \%$ & 38 \\
\hline 3 & $\mathrm{AOP}$ & Sona chemical & 30 & $60 \%$ & 40 \\
\hline 4 & $\mathrm{AOP}$ & Electro chemical & 180 & $100 \%$ & 41 \\
\hline 5 & $\mathrm{AOP}$ & NEAPP + ZnO & 10 & $49 \%$ & This \\
\hline
\end{tabular}

aqueous solution exhibited major absorbance characteristic peak at $260 \mathrm{~nm}$. After, plasma treatment alone, the intensity of the absorbance peak was found be decreased significantly which indicating that $24 \%$ of the VS molecules was decomposed during the processes (Fig. 5b). After plasma degradation carried out at various environment, the intensity of the absorption peak decreased in the order of $\mathrm{P}>\mathrm{P}+$ air $>\mathrm{P}+\mathrm{O}_{2}>$ $\mathrm{P}+\mathrm{H}_{2} \mathrm{O}_{2}$ which indicates an increase in the degradation percentage of VS aqueous solution. The above changes may be correlated to the oxidative degradation of VS molecules in aqueous solution due to the formation of primary $\left(\mathrm{Ar}^{*}, \mathrm{O}_{2}^{*}, \mathrm{e}^{*-}, \mathrm{N}_{2}^{*}\right.$ and $\left.\mathrm{H}_{2} \mathrm{O}^{*}\right)$ and secondary reactive species $\left(\mathrm{OH}, \mathrm{O}, \mathrm{O}_{3}\right.$ and $\left.\mathrm{H}_{2} \mathrm{O}_{2}\right)$ during the plasma degradation processes. Finally, the plasma treatment combined with $\mathrm{ZnO}$ NP's, obtained lower intense of absorbance peak with maximum degradation percentage of $49 \%$ compared to other treatment conditions which mainly caused by the formation of higher concentration of various reactive species during this synergetic process by following facts. Interaction of electron and excited species in plasma with molecules of aqueous solution leads to produce various ROS $\left(\mathrm{e}+\mathrm{H}_{2} \mathrm{O} \rightarrow \mathrm{OH} \cdot+\mathrm{H}^{+}+2 \mathrm{e}, \mathrm{Ar}^{*}+\mathrm{H}_{2} \mathrm{O} \rightarrow\right.$

$\left.\mathrm{Ar}+\mathrm{OH} \bullet+\mathrm{H}, \mathrm{N}_{2}^{*}+\mathrm{H}_{2} \mathrm{O} \rightarrow \mathrm{N}_{2}+\mathrm{OH} \bullet+\mathrm{H}\right)$. In spite of reactive species, high intense of UV photon in plasma has also contributed to produce various reactive species by photocatalysis mechanism. The ZnO NP's in aqueous solution absorbs UV photons and forms an electron and hole pairs $\left(\mathrm{e}_{\mathrm{CB}}^{-}+\mathrm{h}_{\mathrm{VB}}^{+}\right)$. This photo induced electron-hole pair migrate to the surface of $\mathrm{ZnO}$ undergoes redox reaction to produce large number of $\mathrm{OH}^{\cdot}$ radicals, super oxide anion radicals $\left(\mathrm{O}^{2 \cdot-}\right)$ and hydroperoxy radicals $\left(\mathrm{HO}_{2}{ }^{\circ}\right)$ via following reaction.

$$
\begin{gathered}
\mathrm{ZnO}+h \gamma \rightarrow \mathrm{ZnO}\left(\mathrm{e}_{\mathrm{CB}}^{-}+\mathrm{h}_{\mathrm{VB}}^{+}\right) \\
\mathrm{ZnO}\left(\mathrm{h}_{(\mathrm{VB})}^{+}\right)+\mathrm{H}_{2} \mathrm{O} \rightarrow \mathrm{ZnO}+\mathrm{H}^{+}+\mathrm{OH}^{\cdot} \\
\mathrm{ZnO}\left(\mathrm{h}_{(\mathrm{VB})}^{+}\right)+\mathrm{OH}^{-} \rightarrow \mathrm{ZnO}+\mathrm{OH}^{\cdot} \\
\mathrm{ZnO}\left(\mathrm{e}_{(\mathrm{CB})}^{-}\right)+\mathrm{O}_{2} \rightarrow \mathrm{ZnO}+\mathrm{O}^{2 \cdot-} \\
\mathrm{O}^{2 \cdot-}+\mathrm{H}^{+} \rightarrow \mathrm{HO}_{2}^{\cdot} \\
\mathrm{HO}_{2}^{\cdot}+\mathrm{HO}_{2}^{\cdot} \rightarrow \mathrm{H}_{2} \mathrm{O}_{2}+\mathrm{O}_{2} \\
\mathrm{ZnO}_{\left(\mathrm{e}_{(\mathrm{CB})}^{-}\right)}+\mathrm{H}_{2} \mathrm{O}_{2} \rightarrow \mathrm{OH}^{\cdot}+\mathrm{OH}^{-} \\
\mathrm{H}_{2} \mathrm{O}_{2}+\mathrm{O}^{2 \cdot-} \rightarrow \mathrm{OH}^{\cdot}+\mathrm{OH}^{-}+\mathrm{O}_{2}
\end{gathered}
$$

$$
\mathrm{H}_{2} \mathrm{O}_{2}+h v \rightarrow 2 \mathrm{OH}^{\cdot}
$$

In this way higher concentration of various reactive species are produced in the plasma degradation processes combined with ZnO NP's which are facilitated to decompose VS in the aqueous solution. Comparison of degradation of VS by this technique with other treatment methods was given in Table 2. It is evident that combination of NEAPP with ZnO NP's yield higher degradation efficiency within shorter treatment time compared with other AOP due to the formation of higher concentration of reactive species.

\subsection{Detection of $\mathrm{OH}^{-}$and $\mathrm{H}_{2} \mathrm{O}_{2}$ spectroscopy analysis}

In radical chemistry and radiation chemistry $\mathrm{OH}$ radical plays a vital role due to their high oxidative potential $(2.8 \mathrm{~V})$. The quantity of $\mathrm{OH}^{*}$ radicals during the plasma process was analysed by UV-Visible spectroscopy. The UV light can be easily detected with terephthalate, which react with $\mathrm{OH}^{*}$ radicals to form hydroxyl terephthalic acid (fluorescent product) which has fluorescent emission at $425 \mathrm{~nm}$. The intensity of fluorescent emission is proportional to the production of $\mathrm{OH}^{\cdot}$ radicals. The amount of $\mathrm{OH}$ radicals formed during the degradation of VS aqueous solution under different environment such as plasma, air, oxygen, $\mathrm{H}_{2} \mathrm{O}_{2}$ and $\mathrm{ZnO}$ Np's (at constant applied potential of $35 \mathrm{kV}$ and treatment time of $10 \mathrm{~min}$ ) is reported in Fig. 6. In plasma, the excited Ar reacts with aqueous solution and $\mathrm{H}_{2} \mathrm{O}_{2}$ to produce $\mathrm{OH}$ radicals which exhibits the fluorescence emission intensity of 263. During the degradation of VS aqueous solution with different environment, the production of $\mathrm{OH}$ radicals considerably increased and the fluorescence emission intensity follows the order: plasma $<\mathrm{P}+$ air $<\mathrm{P}+\mathrm{O}_{2}<\mathrm{P}+\mathrm{H}_{2} \mathrm{O}_{2}<\mathrm{P}+\mathrm{ZnO}$ at $35 \mathrm{kV}$ and 10 minutes of treatment time. Comparing with various treatment conditions, ZnO NP's shows highest fluorescence intensity of 2123 due to the higher production of $\mathrm{OH}$ radicals during the reaction.

Amount of $\mathrm{H}_{2} \mathrm{O}_{2}$ formed during the degradation of VS in presence of various treatment conditions is depicted in Fig. 7. Generally; high energy electron dissociates the water molecule to produce $\mathrm{H}_{2} \mathrm{O}_{2}$. It is clear from Fig. 7 that the in situ production and external addition of $\mathrm{H}_{2} \mathrm{O}_{2}$ increases the amount of hydrogen per oxide during the reaction. But the concentration of $\mathrm{H}_{2} \mathrm{O}_{2}$ is lower in the case of $\mathrm{ZnO}$ catalyst. The presence of $\mathrm{ZnO}$ catalyst, photo induced electrons and holes dissociated the $\mathrm{H}_{2} \mathrm{O}_{2}$ into $\mathrm{OH}$ radicals. Hence, compared with other condition 


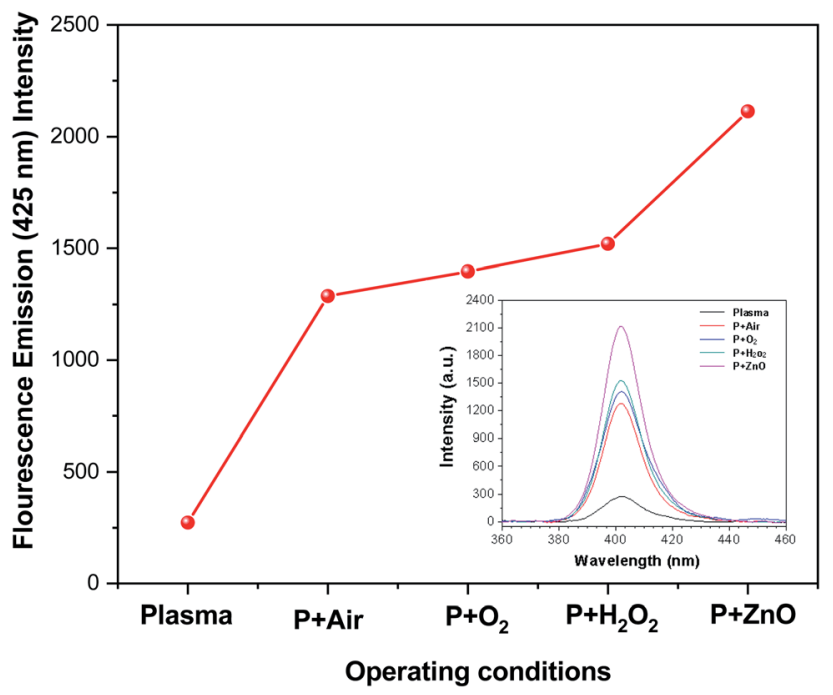

Fig. 6 Concentration of $\mathrm{OH}$ radicals in plasma-treated VS solution with various operating conditions.

$\left(\mathrm{H}_{2} \mathrm{O}_{2}\right)$, the amount of $\mathrm{H}_{2} \mathrm{O}_{2}$ was found to be less in the case of ZnO NP's.

The production of $\mathrm{H}_{2} \mathrm{O}_{2}$ during the reaction is given below

$$
\begin{gathered}
\mathrm{OH}^{\bullet}+\mathrm{OH}^{\bullet} \rightarrow \mathrm{H}_{2} \mathrm{O}_{2} \\
\mathrm{O}+\mathrm{H}_{2} \mathrm{O} \rightarrow \mathrm{H}_{2} \mathrm{O}_{2} \\
\mathrm{OH}^{\bullet}+\mathrm{OH}^{\cdot}+\mathrm{Ar}^{\cdot} \rightarrow \mathrm{H}_{2} \mathrm{O}_{2}+\mathrm{Ar} \\
\mathrm{OH}^{\cdot}+\mathrm{HO}_{2}+\mathrm{Ar}^{\cdot} \rightarrow \mathrm{H}_{2} \mathrm{O}_{2}+\mathrm{O}+\mathrm{Ar}
\end{gathered}
$$

\subsection{Variation of $\mathrm{pH}$, electrical conductivity and TOC}

Fig. 8 depicts the changes in $\mathrm{pH}$ and EC of VS aqueous solution with respect to various treatment conditions. It was observed

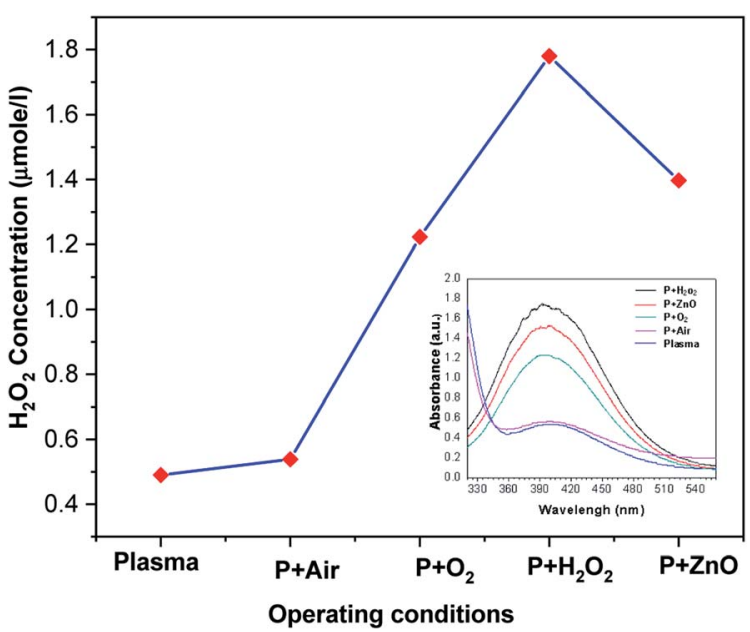

Fig. 7 Concentration of $\mathrm{H}_{2} \mathrm{O}_{2}$ in plasma-treated VS solution with various operating conditions.

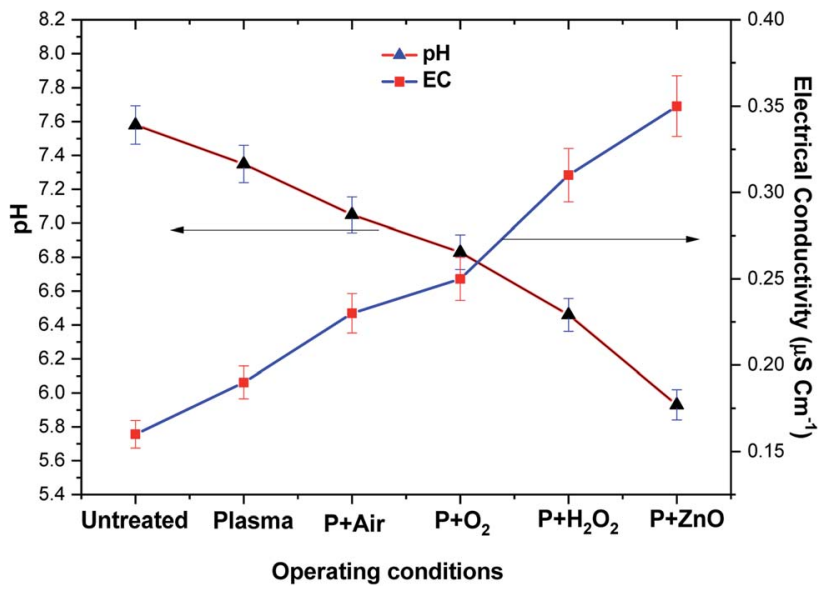

Fig. 8 Electrical conductivity and $\mathrm{pH}$ of VS aqueous solution as a function of various operating conditions.

that the $\mathrm{pH}$ and EC of untreated VS aqueous solution was 7.6 and $0.15 \mu \mathrm{S} \mathrm{cm}^{-1}$. After plasma treatment the $\mathrm{pH}$ of the VS aqueous solution was found to decreased in the order of $\mathrm{P}>\mathrm{P}+$ air $>\mathrm{P}+\mathrm{O}_{2}>\mathrm{P}+\mathrm{H}_{2} \mathrm{O}_{2}>\mathrm{P}+\mathrm{ZnO}$, whereas the conductivity was increased in an opposite trend of $\mathrm{pH}$. The above change may be attributed to the formation of various acid $\left(\mathrm{HNO}_{3}\right.$ and $\left.\mathrm{HNO}_{2}\right)$ and ionic species $\left(\mathrm{NO}^{2-}\right.$ and $\mathrm{NO}^{3-}$ ) in the aqueous solution by conversion of nitrogen containing reactive species such as $\mathrm{N}$, $\mathrm{NO}$ and $\mathrm{NO}_{2}$ during the treatment by the following reaction. ${ }^{42,43}$

$$
\begin{gathered}
\mathrm{N}_{2}+\mathrm{e} \rightarrow \mathrm{N}^{\bullet}+\mathrm{N}^{\bullet} \\
\mathrm{N}^{\bullet}+2 \mathrm{O}^{\bullet} \rightarrow \mathrm{NO}_{2} \\
\mathrm{~N}^{\bullet}+\mathrm{O}_{2} \rightarrow \mathrm{NO}+\mathrm{O}^{\cdot} \\
\mathrm{NO}+\mathrm{O}_{3} \rightarrow \mathrm{NO}_{2}+\mathrm{O}_{2}
\end{gathered}
$$

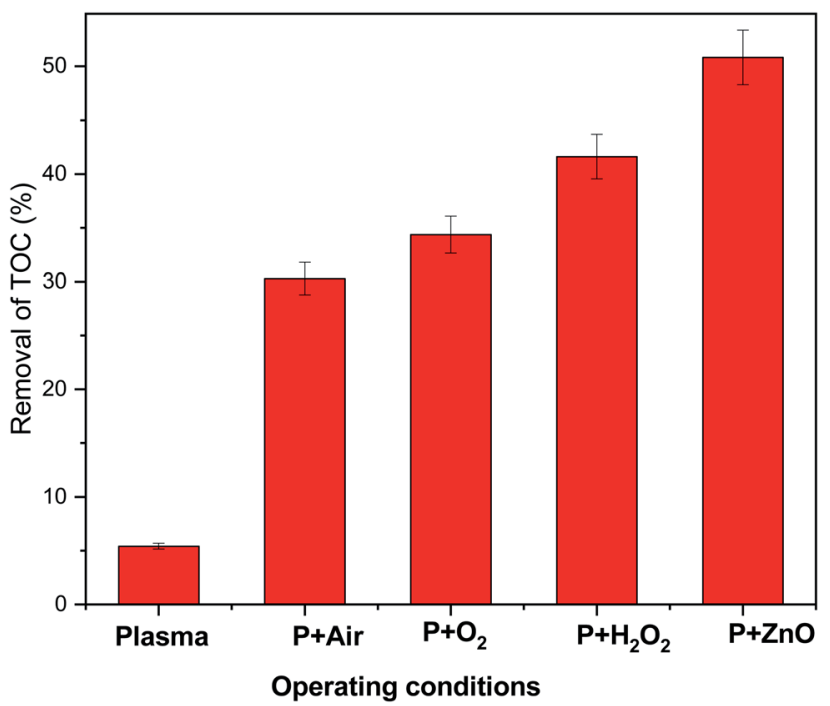

Fig. 9 TOC removal in VS aqueous solution as a function of various operating conditions. 


$$
\begin{gathered}
\mathrm{NO}^{2-}+\mathrm{O}_{3} \rightarrow \mathrm{NO}^{3-}+\mathrm{O}_{2} \\
\mathrm{NO}^{2-}+2 \mathrm{OH}^{\cdot} \rightarrow \mathrm{NO}^{3-}+\mathrm{H}_{2} \mathrm{O} \\
\mathrm{NO}_{2}+\mathrm{OH}^{\cdot} \rightarrow \mathrm{HNO}_{3} \rightarrow \mathrm{H}^{+}+\mathrm{NO}^{3-} \\
\mathrm{NO}+\mathrm{OH}^{\cdot} \rightarrow \mathrm{HNO}_{2} \rightarrow \mathrm{H}^{+}+\mathrm{NO}^{2-}
\end{gathered}
$$

The mineralization of VS aqueous solution by various plasma treatment condition were examined by measuring elimination of TOC in aqueous solution (Fig. 9). It was observed that $5.43 \%$ of TOC was removed from the VS aqueous solution by Ar plasma treatment alone and was found to be increased by the degradation processes carried out by the following order $\mathrm{P}<$ $\mathrm{P}+$ air $<\mathrm{P}+\mathrm{O}_{2}<\mathrm{P}+\mathrm{H}_{2} \mathrm{O}_{2}<\mathrm{P}+\mathrm{ZnO}$, this may be due to formation of various reactive species during the processes. The obtained reactive species further dissociate/oxidized the carbon network of an organic compounds into small fragments of carbon molecules which may be further converted into various acid and finally to carbon dioxide $\left(\mathrm{CO}_{2}\right)$. The variation in $\mathrm{pH}$, electrical conductivity and TOC removal percentage clearly implies that the mineralization of VS aqueous solution was achieved by plasma treatment. ${ }^{44}$

\section{Conclusion}

The NEAPP in an aqueous solution containing pharmaceutical drug VS with ZnO NP's showed higher degradation (\%) compared with other treatment conditions such as plasma alone, air, $\mathrm{O}_{2}$ and $\mathrm{H}_{2} \mathrm{O}_{2}$ due to the formation of higher concentration of ROS confirmed by spectroscopic analysis. Moreover, a decrease in $\mathrm{pH}$, increase in conductivity and percentage of TOC removal results supports that substantial degradation of VS aqueous solution in the order of $\mathrm{P}<\mathrm{P}+$ air $<\mathrm{P}$ $+\mathrm{O}_{2}<\mathrm{P}+\mathrm{H}_{2} \mathrm{O}_{2}<\mathrm{P}+\mathrm{ZnO}$. Finally, we conclude that VS degradation carried out by the combination of plasma with catalyst exhibited significant efficacy than other treatment conditions.

\section{Conflicts of interest}

There are no conflicts to declare.

\section{Acknowledgements}

The corresponding author Dr K. Navaneetha Pandiyaraj is grateful for the financial assist afforded by Science and Engineering Research Board (SERB) (EMR/2016/006812 Dated: 02Nov-2017), Department of Science and Technology (DST), Government of India.

\section{References}

1 D. Pimentel, S. Cooperstein, H. Randell, D. Filiberto, S. Sorrentino, B. Kaye, C. Nicklin, J. Yagi, J. Brian,
J. O'Hern, A. Habas and C. Weinstein, Hum. Ecol., 2007, 35, 653-668.

2 F. Latif, S. Tandon, R. Obeleniene, S. R. Hankins, M. S. Berlowitz, P. V. Ennezat and T. H. Le Jemtel, J. Card. Failure, 2001, 7, 265-268.

3 D. Martínez-Pachón, P. Espinosa-Barrera, J. Rincón-Ortíz and A. Moncayo-Lasso, Environ. Sci. Pollut. Res., 2019, 26, 4426-4437.

4 J. Trawiński and R. Skibiński, Environ. Sci. Pollut. Res., 2017, 24, 1152-1199.

5 K. A. Kidd, P. J. Blanchfield, K. H. Mills, V. P. Palace, R. E. Evans, J. M. Lazorchak and R. W. Flick, Proc. Natl. Acad. Sci. U. S. A., 2007, 104, 8897-8901.

6 M. del Rosario Brunetto, Y. Contreras, S. Clavijo, D. Torres, Y. Delgado, F. Ovalles, C. Ayala, M. Gallignani, J. M. Estela and V. C. Martin, J. Pharm. Biomed. Anal., 2009, 50, 194-199.

7 S. L. Klosterhaus, R. Grace, M. C. Hamilton and D. Yee, Environ. Int., 2013, 54, 92-99.

8 L. H. M. L. M. Santos, M. Gros, S. Rodriguez-Mozaz, C. Delerue-Matos, A. Pena, D. Barceló and M. C. B. S. M. Montenegro, Sci. Total Environ., 2013, 461462, 302-316.

9 C. Babu Patneedi, D. K. Prasadu, R. S. K Sharma, D. Chandra Sekhar and D. Venkata Rao Visakhapatnam, Rasayan J. Chem., 2015, 8, 176-185.

10 B. Silva, F. Costa, I. C. Neves and T. Tavares, Psychiatric Pharmaceuticals as Emerging Contaminants in Wastewater, Springer International Publishing, Cham, 2015.

11 N. Vieno and M. Sillanpaa, Environ. Int., 2014, 69, 28-39.

12 M. M. Huber, S. Canonica, G. Y. Park and U. Von Gunten, Environ. Sci. Technol., 2003, 37, 1016-1024.

13 M. Perez-Moya, M. Graells, G. Castells, J. Amigo, E. Ortega, G. Buhigas, L. M. Perez and H. D. Mansilla, Water Res., 2010, 44, 2533-2540.

14 X. He, S. P. Mezyk, I. Michael, D. Fatta-Kassinos and D. D. Dionysiou, J. Hazard. Mater., 2014, 279, 375-383.

15 M. Jovic, D. Manojlovic, D. Stankovic, B. Dojcinovic, B. Obradovic, U. Gasic and G. Roglic, J. Hazard. Mater., 2013, 260, 1092-1099.

16 H. Dong, G. Zeng, L. Tang, C. Fan, C. Zhang, X. He and Y. He, Water Res., 2015, 79, 128-146.

17 M. Markovic, M. Jovic, D. Stankovic, V. Kovacevic, G. Roglic, G. Gojgic-Cvijovic and D. Manojlovic, Sci. Total Environ., 2015, 505, 1148-1155.

18 Ruma, N. Aoki, T. Sakugawa, H. Akiyama and M. Akiyama, IEEJ Trans. Fundam. Mater., 2013, 133, 636-641.

19 J. M. Herrmann, Catal. Today, 1999, 53, 115-129.

20 N. Kaneva, I. Stambolova, V. Blaskov, Y. Dimitriev, A. Bojinova and C. Dushkin, Surf. Coat. Technol., 2012, 207, 5-10.

21 M. Trojanowicz, I. Bartosiewicz, A. Bojanowska-Czajka, K. Kulisa, T. Szreder, K. Bobrowski, H. Nichipor, J. F. Garcia-Reyes, G. Nałęcz-Jawecki, S. MęczynskaWielgosz and J. Kisała, Chem. Eng. J., 2019, 357, 698-714.

22 E. Janardhan, M. Maheshwar Reddy, P. Venkat Reddy and M. Jaipal Reddy, Eur. J. Appl. Sci., 2017, 9, 312-314. 
23 K. N. Pandiyaraj, D. Vasu, P. V. A. Padmanabhan, M. Pichumani, R. R Deshmukh and V. Kandavelu, Plasma Sci. Technol., 2020, 22, 055504.

24 S. Kanazawa, T. Furuki, S. Akamine and R. Ichiki, Measurement of $\mathrm{OH}$ Radicals in Aqueous Solution Produced by Atmospheric-pressure LF Plasma Jet, Int. J. Plasma Environ. Sci. Technol., 2012, 6, 166-171.

25 S. E. Page, W. A. Arnold and K. McNeill, J. Environ. Monit., 2010, 12, 1658-1665.

26 R. F. P. Nogueira, M. C. Oliveira and W. C. Paterlini, Talanta, 2005, 66, 86-91.

27 R. M. Sellers, Analyst, 1980, 105, 950-954.

28 D. Vasu, K. Navaneetha Pandiyaraj, P. V. A. Padmanabhan, M. Pichumani, R. R. Deshmukh and S. K. Jaganathan, Environ. Geochem. Health, 2019, 1-14.

29 D. Florescu, A. M. D. Costinel, E. Horj, R. E Ionete and M. Culea, Rom. J. Phys., 2013, 58, 211-219.

30 K. Navaneetha Pandiyaraj, D. Vasu, P. V. A. Padmanabhan, R. Ghobeira, P. S. Esbah Tabaei, P. Cools, N. De Geyter, R. Morent, R. R. Deshmukh and M. Pichumani, Synergetic effect of the catalytic action of plasma jet deposited TiOx coatings and atmospheric pressure plasma treatment on the degradation of RYRR, Surf. Coat. Technol., 2020, 389, 125642.

31 A. Zamiri, G. Rebelo, G. Zamiri, A. Adnani, A. Kuashal, M. S. Belsleyd and J. M. F. Ferreira, RSC Adv., 2014, 4, 20902-20908.

32 R. Wahab, S. G. Ansari, Y. S. Kim, H. K. Seo, G. S. Kim, G. Khang and H. S. Shin, Mater. Res. Bull., 2007, 42, 16401648.
33 P. Attri, Y. H. Kim, D. H. Park, J. H. Park, Y. J. Hong, H. S. Uhm, K. N. Kim, A. Fridman and E. H. Choi, Sci. Rep., 2015, 5, 9332.

34 F. Rezaei, Y. Gorbanev, M. Chys, A. Nikiforov, S. W. H. Van Hulle, P. Cos, A. Bogaerts and N. De Geyter, Plasma Processes Polym., 2018, 15(6), 1700226.

35 A. Barkhordari, A. Ganjovi, I. Mirzaei, A. Falahat and M. N. Rostami Ravari, J. Theor. Appl. Phys., 2017, 11, 301-312.

36 I. Onyshchenko, A. Y. Nikiforov, N. De Geyter and R. Morent, Plasma Processes Polym., 2015, 12, 466-476.

37 M. C. Huang, T. Wang, B. J. Wu, J. C. Lin and C. C. Wu, Appl. Surf. Sci., 2016, 360, 442-450.

38 D. M. Pachón, P. E. Barrera, J. R. Ortíz and A. M. Lasso, Environ. Sci. Pollut. Res., 2019, 26, 4426-4437.

39 D. Martinez-Pachón, M. Ibanez, F. Hernandez, R. A. TorresPalma and A. Moncayo-Lasso, J. Environ. Chem. Eng., 2018, 6, 7302-7311.

40 E. A. Serna-Galvis, L. Isaza-Pineda, A. Moncayo-Lasso, F. Hernandez, M. Ibanez and R. A. Torres-Palma, Ultrason. Sonochem., 2019, 58, 104635.

41 C. Salazar, N. Contreras, H. D. Mansilla, J. Yáñez and R. Salazar, J. Hazard. Mater., 2016, 319, 84-92.

42 T. Wang, G. Qu, J. Ren, Q. Sun, D. Liang and S. Hu, J. Hazard. Mater., 2016, 302, 65-71.

43 K. S. Kim, S. K. Kam and Y. S. Mok, Chem. Eng. J., 2015, 271, 31-42.

44 P. M. K Reddy and Ch. Subrahmanyam, Ind. Eng. Chem. Res., 2012, 34, 11097-11103. 